\title{
Allergic lung inflammation induces pulmonary vascular hyperresponsiveness
}

\author{
M. Witzenrath*, B. Ahrens”, S.M. Kube*, A.C. Hocke*, S. Rosseau*, E. Hamelmann\#, \\ N. Suttorp* and H. Schütte*
}

ABSTRACT: Pulmonary arterial vasoconstriction is an important early component of pulmonary hypertension. Inflammatory mechanisms play a prominent role in the pathogenesis of pulmonary hypertension. The present authors investigated the potential role of acute allergic lung inflammation for alterations in pulmonary haemodynamics.

BALB/c mice were intraperitoneally sensitised to ovalbumin and challenged by ovalbumin inhalation. Subsequently, lungs were ventilated and perfused ex vivo, and pulmonary arterial pressure $(\mathrm{Ppa})$ was continuously monitored.

Isolated perfused lungs of allergen-sensitised and -challenged mice showed five-fold enhanced Ppa responses to serotonin, which is reported to be a significant contributor to pulmonary hypertension in humans. This increase in $P$ pa was abolished by the serotonin receptor-2A antagonist ketanserin, but not the serotonin receptor-1B antagonist GR127935. Intracellular signalling to serotonin involved phosphatidylcholine-specific phospholipase $C$ and protein kinase C, as well as Rho-kinase, as assessed by employing the specific inhibitors D609, bisindolylmaleimide and Y27632, respectively. In addition to serotonin, impressively enhanced $P$ pa increases in allergic lungs were also evoked by the thromboxane receptor agonist U46619, angiotensin II and endothelin-1.

In conclusion, allergic lung inflammation was accompanied by impressive pulmonary vascular hyperresponsiveness. These results suggest a possible role for allergic inflammation in the development of pulmonary arterial hypertension.

KEYWORDS: Allergic inflammation, 5-hydroxytryptamine, isolated mouse lung, ovalbumin, pulmonary hypertension, serotonin

I $\mathrm{n}$ inflammatory airway disorders, inflammation is not restricted to the airways, but may also affect pulmonary vessels. Examination of lungs from patients who died during an asthma attack revealed that inflammation, including eosinophilia, involves the tissue and large pulmonary arteries adjacent to bronchi [1]. Moreover, in lungs from long-term smokers, morphological changes in pulmonary arteries in parallel with small airway disease and emphysema were found [2], and inflammatory mechanisms are assumed to contribute to alterations of the pulmonary circulation in chronic obstructive pulmonary disease (COPD) [3,4]. Against this background, it is noteworthy that a variety of autoimmune disorders and infectious diseases have been reported to be associated with pulmonary arterial hypertension (PAH) [5]. Taken together, inflammatory mechanisms may, therefore, play an important role in the pathogenesis of PAH [5].

Structural and functional changes of the pulmonary circulation in PAH include remodeling of the pulmonary arterial wall, endothelial dysfunction and thrombosis [6], as well as pulmonary vasoconstriction, which is assumed to be an important early component of the hypertensive process [7]. In this context, the vasoconstrictive agent serotonin (5-hydroxytryptamine; 5-HT) has been identified as a relevant contributor to PAH [7]. Medication with the appetite suppressants aminorex fumarate and fenfluramine, resulting in elevated plasma 5-HT, was associated with an increased incidence of $\mathrm{PAH}[8,9]$, but the predisposing factors that are essential for the manifestation of the disease are unknown [10].

In order to model pulmonary hypertension in rodents, intravascular monocrotaline application has been widely used, leading to neutrophilic pulmonary vascular inflammation, pulmonary hypertension and cor pulmonale [11]. Perivascular immune responses with leukocyte infiltration were also observed in a variety of airway inflammation models [12]. In particular, in a mouse model of allergic airway inflammation, extensive
AFFILIATIONS

*Dept of Internal Medicine, Infectious Diseases and Respiratory Medicine, and

${ }^{*}$ Dept of Paediatric Pneumology and Immunology, Charité,

Universitätsmedizin Berlin, Berlin, Germany.

CORRESPONDENCE M. Witzenrath

Dept of Internal Medicine

Infectious Diseases and Respiratory Medicine

Charité

Universitätsmedizin Berlin

Schumannstr 20/21

10117 Berlin

Germany

Fax: 4930450553979

E-mail: martin.witzenrath@charite.de

Received:

July 082005

Accepted after revision:

March 192006

SUPPORT STATEMENT

The present study was supported in part by grants from the

Bundesministerium für Bildung und Forschung to S. Rosseau and N. Suttorp (CAPNETZ - competence network community-acquired pneumonia) and E. Hamelmann (01 ZZ 01042000). 
eosinophil and mononuclear cell infiltrates were seen around the pulmonary blood vessels $[13,14]$, and a recent study in mice showed that central features of allergen-induced airway remodeling were also present in the pulmonary vessels, including smooth muscle enlargement [15]. These findings provide further evidence that, beyond airway alterations, allergic inflammation may also affect the pulmonary vascular bed. However, the functional consequences of these findings remain unknown.

In the current study, it was observed that allergen-induced lung inflammation induced increased pulmonary arterial pressor responses to 5-HT measured in isolated perfused mouse lungs. The present authors investigated the contribution of the 5-HT2A and 5-HT1B/D receptor, addressed the 5-HT specificity of the observed phenomenon, and analysed the intracellular signalling pathways related to the 5-HT induced pulmonary vascular responses.

\section{METHODS}

\section{Allergen sensitisation and challenge}

All experimental procedures were approved by local authorities. Pathogen-free female BALB/c mice (20-23 g; BgVV, Berlin, Germany) were maintained on an ovalbumin (OVA)free diet. Systemic sensitisation with OVA $\left(20 \mu \mathrm{g} \cdot\right.$ injection $^{-1}$; Sigma, Deisenhofen, Germany) adsorbed to $2 \mathrm{mg} \mathrm{Al}(\mathrm{OH})_{3}$ (Pierce, Rockford, IL, USA) by i.p. injections on days 0 and 14, and repeated airway challenges with aerosolised 1\% OVA (weight/volume) in PBS (20 min) on days 28, 29 and 30 were performed as described [16] (fig. 1).

\section{Preparation of bronchoalveolar lavage fluid}

Animals were killed $24 \mathrm{~h}$ after the last airway challenge, and the tracheas were cannulated. Airways underwent lavage twice with $1 \mathrm{~mL}$ of ice-cold PBS, and cell numbers were determined as previously described [17]. Total leukocytes, lymphocytes, eosinophils and macrophages were differentiated in bronchoalveolar lavage fluid (BALF) according to morphological criteria [17].

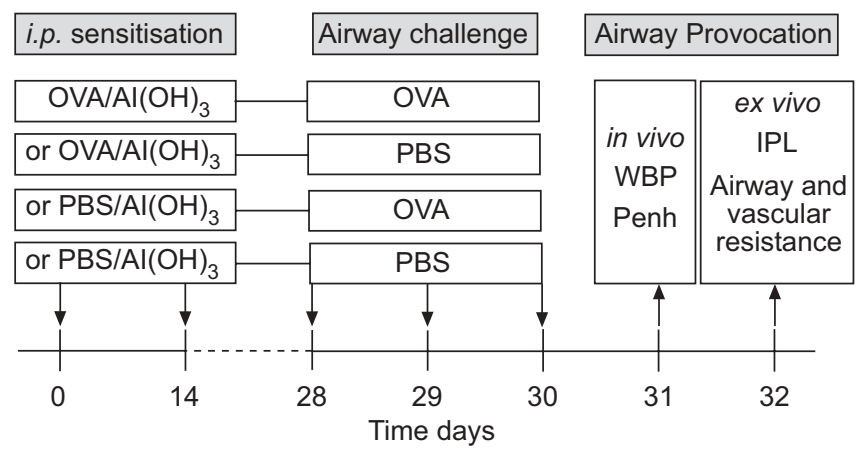

FIGURE 1. Diagram to show the animal treatment protocol. Mice were sensitised to ovalbumin (OVA) adsorbed to $\mathrm{Al}(\mathrm{OH})_{3}$, by i.p. injections or received vehicle on days 0 and 14 . On indicated days, airway challenges were performed with 1\% OVA or solvent (PBS), delivered by aerosolisation for $20 \mathrm{~min}$. The airway response to methacholine was measured in vivo on day 31 by means of whole body plethysmography (WBP) determining "enhanced pause" (Penh). On day 32, ex vivo airway and vascular responses were determined in the isolated perfused and ventilated mouse lung (IPL).

\section{Histochemistry}

Lung tissue was fixed in $4 \%$ formalin, dehydrated, mounted in paraffin, sectioned and stained with periodic acid-Schiff (PAS) reaction using a standard protocol.

\section{Serum levels of total and OVA-specific immunoglobulin $E$} On day 31, serum levels of total and OVA-specific immunoglobulin (Ig)E were measured by means of ELISA, as previously described [18]. Levels of OVA-specific IgE were related to pooled standards generated in the authors' laboratory and expressed as arbitrary units per $\mathrm{mL}$. Total serum IgE (Sigma, Taufkirchen, Germany) levels were calculated by comparison with known mouse $\operatorname{IgE}$ standards and expressed in $\mathrm{ng} \cdot \mathrm{mL}^{-1}$.

\section{In vivo airway responsiveness}

Airway responsiveness (AR) was measured in unrestrained animals by barometric whole body plethysmography (BuxCO ${ }^{\circledR}$; EMKA Technologies, Paris, France) as described elsewhere [16]. As an index of in vivo airway obstruction, enhanced pause (Penh) values were calculated [16].

\section{Isolated perfused mouse lung}

Mouse lungs were prepared as described previously [19, 20]. Lungs were perfused with $37^{\circ} \mathrm{C}$ sterile Krebs-Henseleithydroxyethylamylopectine buffer $\left(1 \mathrm{~mL} \cdot \mathrm{min}^{-1}\right.$; SeragWiesner, Naila, Germany) in a nonrecirculating fashion, and left atrial pressure was adjusted at $+2.2 \mathrm{cmH}_{2} \mathrm{O}$. Pulmonary arterial pressure $(\mathrm{Ppa})$ and venous pressure were continuously monitored and digitised. Following isolation, lungs were ventilated by constant negative pressure (expiration: $4.5 \mathrm{cmH}_{2} \mathrm{O}$ to inspiration $-9.0 \mathrm{cmH}_{2} \mathrm{O} ; 90$ breaths $\left.\cdot \mathrm{min}^{-1}\right)$ in a closed chamber. Hyperinflation $\left(-24 \mathrm{cmH}_{2} \mathrm{O}\right)$ was performed at 4-min intervals. The chamber pressure was continuously measured by a differential pressure transducer, and airflow velocity was monitored by means of a pneumotachograph connected to a second differential pressure transducer. Signals were amplified and registered with Pulmodyn ${ }^{\circledR}$ software, and the data for airway resistance (Raw) were analysed as described previously [21]. All hardware and software were purchased from HSE Harvard Apparatus, March-Hugstetten, Germany.

\section{Airway and vascular responsiveness in isolated perfused mouse lung}

After a steady state period of $30 \mathrm{~min}, 5-\mathrm{HT}$ (Sigma, Taufkirchen, Germany) or, alternatively, the thromboxane receptor agonist U46619, angiotensin II or endothelin-1 (all Calbiochem, Darmstadt, Germany) were administered to the perfusate for $30 \mathrm{~s}, 3,2$ or $10 \mathrm{~min}$, respectively. The concentration of either agent was increased in 12-min intervals. Raw and $P$ pa were determined $30 \mathrm{~s}$ before and at the respective maximum response after 5-HT, U46619, angiotensin II or endothelin-1 administration. The change in Raw was expressed as fold $R$ aw, and the difference in $P$ pa $(\Delta P$ pa $)$ was expressed in $\mathrm{cmH}_{2} \mathrm{O}$.

Ketanserin (1 $\mu \mathrm{M}$; Sigma, Taufkirchen, Germany), GR127935 (0.1 $\mu \mathrm{M}$; donated by GlaxoSmithKline, Munich, Germany), D609 (100 $\mu \mathrm{M}$; Sigma), xestospongin C (1 $\mu \mathrm{M}$; Biomol, Hamburg, Germany), bisindolylmaleimide $(10 \mu \mathrm{M})$, or Y27632 (5 $\mu \mathrm{M}$; both Calbiochem, Darmstadt, Germany) were administered to the perfusate $10 \mathrm{~min}$ prior to 5 -HT application. 


\section{Data analysis}

Data are expressed as mean \pm SEM. Differences were analysed by ANOVA, followed by post hoc Student-Newman-Keuls test.

\section{RESULTS}

\section{Allergen-induced lung inflammation}

On day 31, allergen-induced lung inflammation was evaluated. The total number of cells, as well as the number of eosinophils and lymphocytes, was increased in BALF of OVA/OVA mice compared with all other groups (fig. 2a). Plasma levels of total IgE and OVA-specific IgE were increased in OVA-sensitised animals compared with PBS/PBS and PBS/OVA animals (fig. 2b). OVA/OVA mice showed increased in vivo AR, whereas OVA/PBS, PBS/OVA and PBS/PBS treated mice displayed low AR, as assessed by measuring Penh in unrestrained animals by barometric whole body plethysmography after inhalative challenges with increasing methacholine doses (data not given). PAS stained lung sections of OVA/OVA mice revealed peribronchial and perivascular infiltrates (fig. 2c).

\section{Airway and vascular responsiveness to 5-HT in isolated perfused mouse lung}

On day 32 of the protocol, lungs were ventilated and perfused ex vivo. 5-HT infusion induced a large, rapid and dosedependent $P$ pa increase in the lungs of OVA-sensitised and OVA-challenged mice, whereas lungs of all control groups displayed only minor Ppa changes (fig. 3a). Lungs of OVA/ OVA mice responded immediately to 5-HT perfusion, with $P$ pa peaking after $1 \mathrm{~min}$ and reaching baseline values within $<4$ min $\left(\leqslant 10^{-5} \mathrm{M} 5\right.$-HT) or within $10-20 \mathrm{~min}\left(10^{-4} \mathrm{M} 5-\mathrm{HT}\right)$. Importantly, in the isolated lungs, neither baseline $P$ pa values (OVA/OVA $8.83 \pm 0.23 \mathrm{cmH}_{2} \mathrm{O}$; OVA/PBS 9.28 $\pm 0.31 \mathrm{cmH}_{2} \mathrm{O}$; PBS/OVA $7.98 \pm 0.50 \mathrm{cmH}_{2} \mathrm{O}$; PBS/PBS $\left.8.79 \pm 0.37 \mathrm{cmH}_{2} \mathrm{O}\right)$, nor baseline values for airway resistance (OVA/OVA $1.50 \pm 0.06$
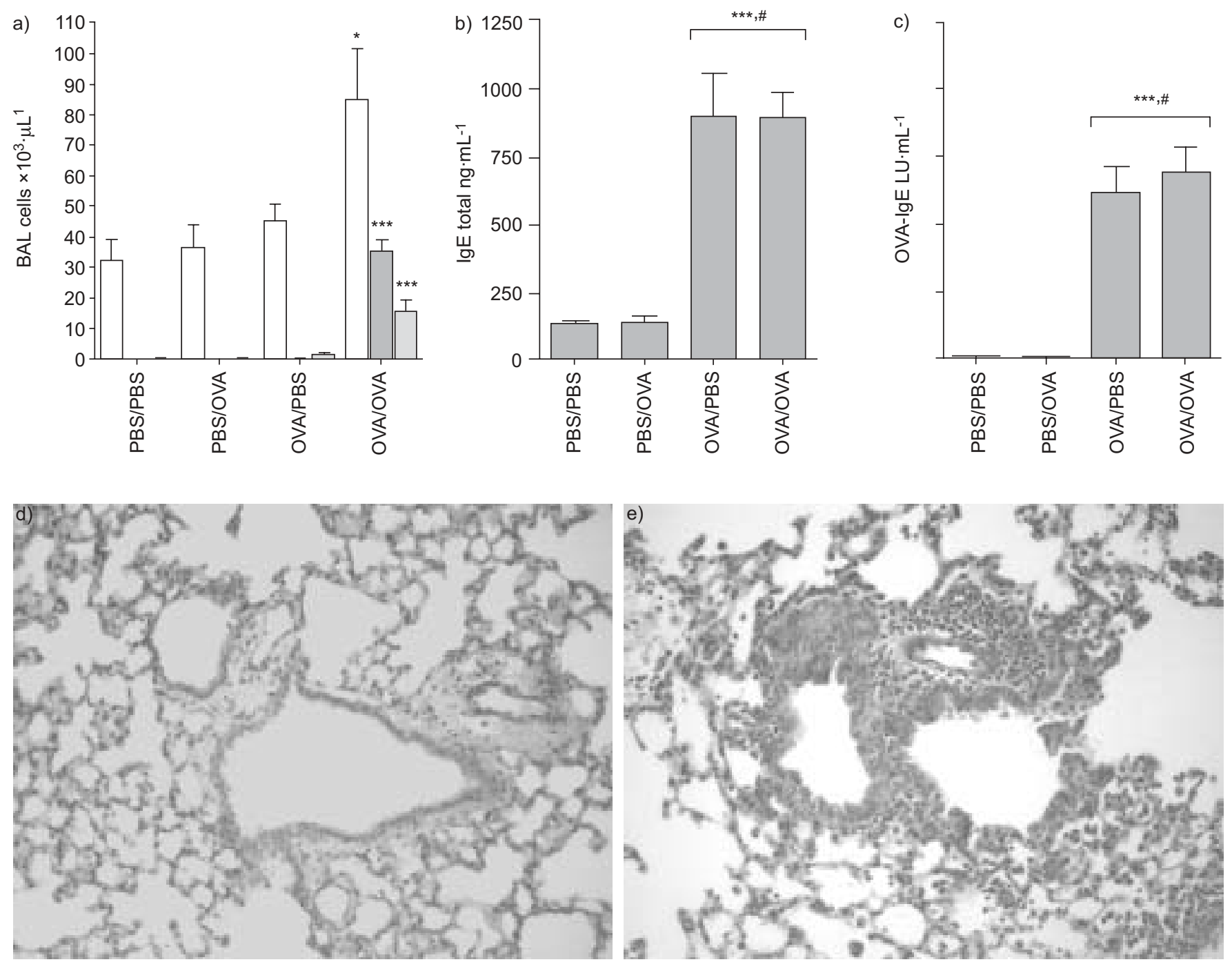

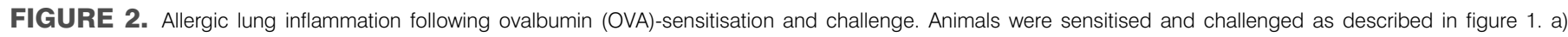

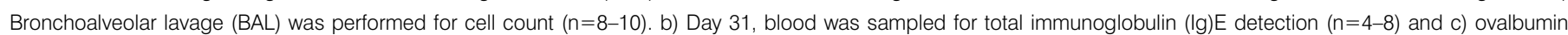

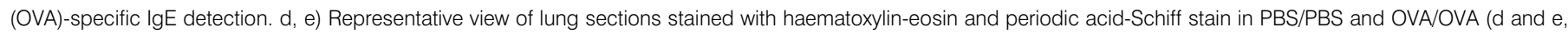

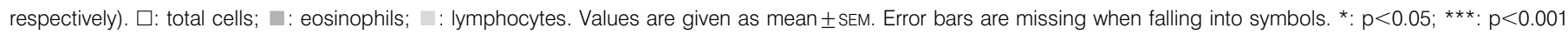
versus all other groups. ${ }^{*}: \mathrm{p}<0.001$ versus PBS/OVA. 
$\mathrm{cmH}_{2} \mathrm{O} \cdot \mathrm{s}^{-1} \cdot \mathrm{mL}^{-1} ;$ OVA/PBS $1.52 \pm 0.08 \mathrm{cmH}_{2} \mathrm{O} \cdot \mathrm{s} \cdot \mathrm{mL}^{-1}$; PBS/ OVA $1.68 \pm 0.06 \mathrm{cmH}_{2} \mathrm{O} \cdot \mathrm{s} \cdot \mathrm{mL}^{-1}$; PBS/PBS $1.55 \pm 0.08 \mathrm{cmH}_{2} \mathrm{O} \cdot \mathrm{s} \cdot$ $\mathrm{mL}^{-1}$ ) differed between the experimental groups. Isolated lungs of allergen-sensitised and -challenged mice showed enhanced AR to 5-HT as compared with all other experimental groups (fig. 3b).

\section{5-HT induced vasoconstriction is mediated via the $5-H T 2 A$ receptor}

The current authors then analysed whether 5-HT contributed to the development of acute pulmonary vasoconstriction via the Gi-coupled 5-HT1 receptor or via the Gq-coupled 5-HT2A receptor. The specific 5-HT2A receptor antagonist ketanserin reduced the $5-\mathrm{HT}$-induced $P$ pa responses by $>95 \%$. In contrast, the 5-HT1-specific receptor antagonist GR127935 [22] did not affect the pressor response to 5-HT, neither in lungs from OVA-sensitised and -challenged mice nor in lungs from nonsensitised, nonchallenged controls (fig. 4).
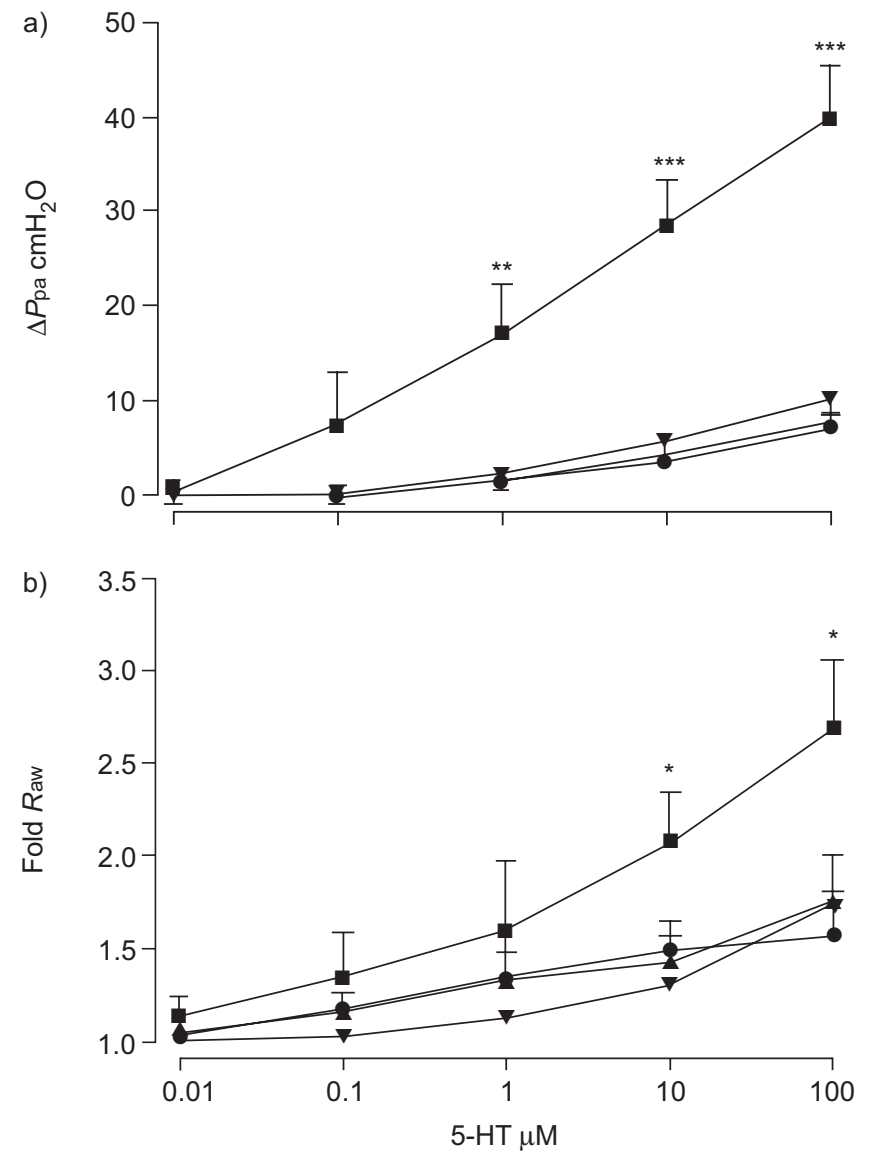

FIGURE 3. Increase of pulmonary arterial pressure $(P$ pa) and airway resistance (Raw) in response to 5-hydroxytryptamine (5-HT) in isolated mouse lungs. Mice were sensitised and challenged as described in figure 1. Perfusion of the isolated lung was repetitively changed to buffer $5-\mathrm{HT}$ ( $30 \mathrm{~s}$ each dose). Ppa (a) and Raw (b) were determined considering values $30 \mathrm{~s}$ before $5-\mathrm{HT}$ perfusion and at maximum $P \mathrm{pa}$ and Raw, respectively. $\mathbf{\square}$ : ovalbumin (OVA)/OVA; $\bullet:$ PBS/PBS; $\mathbf{\Lambda}$ : OVA/PBS; $\boldsymbol{\nabla}$ PBS/OVA. Values are given as mean \pm SEM $(n=6$ each). Error bars are missing when falling into symbols. ${ }^{*}: p<0.05 ;{ }^{* *}: p<0.01 ;{ }^{* \star *}: p<0.001$ versus all other groups.

\section{Vascular hyperresponsiveness in isolated perfused mouse lungs is not $\mathbf{5 - H T}$ specific}

Similarly to 5-HT, the vasoconstrictors thromboxane A2, angiotensin II and endothelin-1 act via Gq-coupled receptors. When lungs were perfused with the thromboxane receptor agonist U46619 $\left(3 \times 10^{-9}\right.$ to $\left.3 \times 10^{-8} \mathrm{M}\right), P$ pa in OVA/OVA lungs increased manifold as compared with all other groups (fig. 5a). Interestingly, AR to U46619 in OVA/OVA lungs was not different from all other groups (fig. 5b). Furthermore, in response to angiotensin II and endothelin-1, Ppa in OVA/ OVA lungs showed higher increases compared with PBS/PBS lungs (fig. 5c and d).

\section{Pressor response to 5-HT in OVA/OVA lungs mediated via phosphatidylcholine-specific phospholipase $C$ and protein kinase C}

Finally, the intracellular cascade involved in the signalling downstream of 5-HT was investigated. Pre-treatment of perfused OVA/OVA lungs with the phosphatidylcholinespecific phospholipase C (PC-PLC) inhibitor D609 largely attenuated the pressor responses to 5-HT (fig. 6). As D609 additionally inhibits sphingomyelin synthase [23], the current authors excluded a major importance of sphingomyelin synthesis for the pressor response by using the sphingomyelinase inactivator imipramine [24]. Imipramine did not significantly reduce the $P$ pa increase to 5-HT (5-HT: $46.5 \pm 10.83 \mathrm{cmH}_{2} \mathrm{O}$; 5-HT+imipramine: $36.81 \pm 11.57 \mathrm{cmH}_{2} \mathrm{O}$; $\mathrm{p}=0.69$ ), suggesting that the pressor response depended on PC-PLC rather than sphingomyelin. Inhibition of a downstream effector of PC-PLC, inositol-1,4,5-triphosphate $\left(\mathrm{IP}_{3}\right)$,

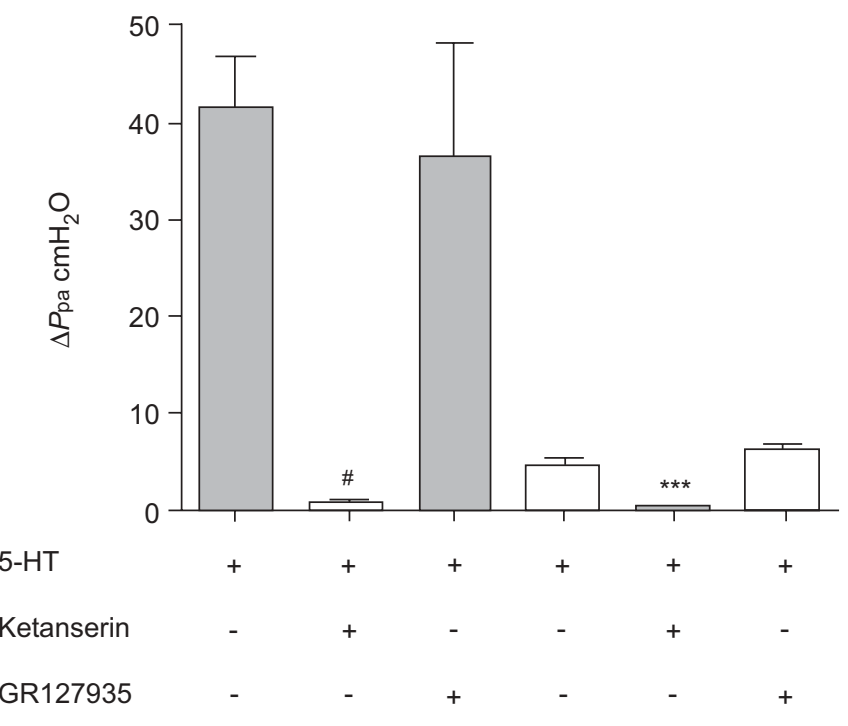

FIGURE 4. Increase of pulmonary arterial pressure $(\mathrm{Ppa})$ in response to 5 hydroxytryptamine $(5-\mathrm{HT})$ perfusion in presence or absence of the $5-\mathrm{HT} 1 \mathrm{~B}$ receptor antagonist GR127935 $(0.1 \mu \mathrm{M})$, or the 5 -HT2A receptor antagonist ketanserin (1 $\mu \mathrm{M})$. Mice were sensitised and challenged according to the protocol depicted in figure 1. Inhibitors were infused starting $10 \mathrm{~min}$ prior to perfusion with 5-HT (100 $\mu \mathrm{M})$. Difference in $\mathrm{Ppa}(\triangle \mathrm{Ppa})$ was determined considering values $30 \mathrm{~s}$ before $5-\mathrm{HT}$ perfusion and at maximum $P$ pa. $\square$ : PBS/PBS; $\square$ : ovalbumin (OVA)/OVA. Data are presented as mean \pm SEM $\left(n=4\right.$ each). ${ }^{*}: p<0.001$ versus $5-\mathrm{HT}$ - and $5-\mathrm{HT} /$ GR127935-exposed OVA/OVA lungs; ***: $p<0.001$ versus 5 -HT- and $5-\mathrm{HT} /$ GR127935-exposed PBS/PBS lungs. 

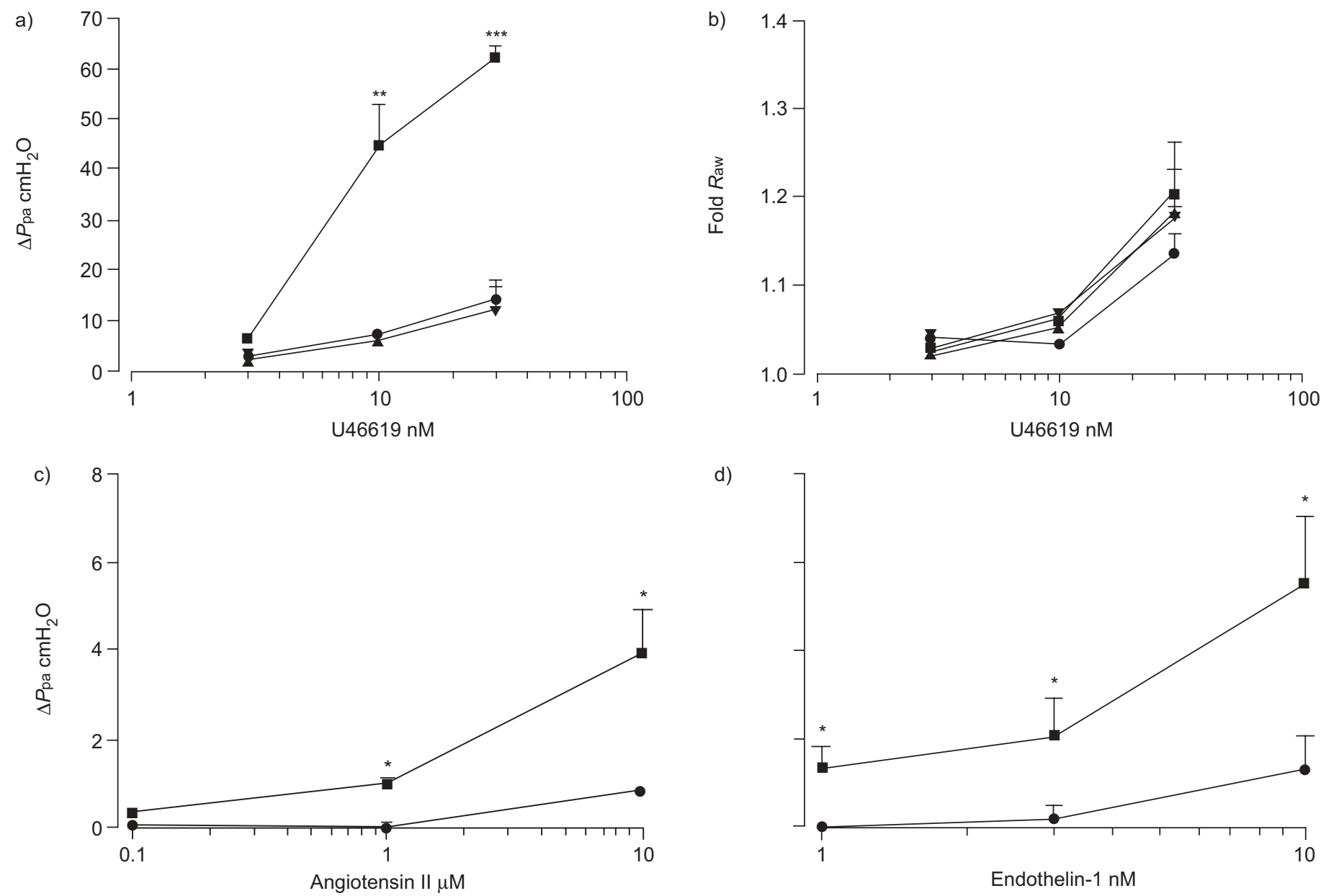

d)

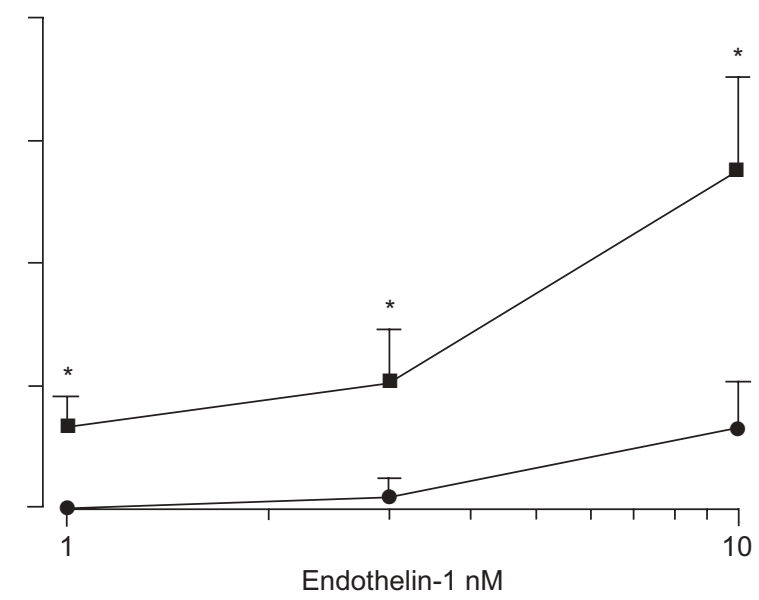

FIGURE 5. Increase of pulmonary arterial pressure (Ppa) in isolated mouse lungs in response to a) U46619 c) angiotensin II, d) endothelin-1, and b) airway resistance (Raw) in response to U46619. Mice were sensitised and challenged as described in figure 1. Perfusion of the isolated lung was repetitively changed to buffer containing U46619 (3 min each dose), angiotensin II (2 min) or endothelin-1 (10 min). Difference in Ppa ( $\triangle P$ pa; a c, d) and Raw (b) was determined considering values $30 \mathrm{~s}$ before perfusion with any agent and at maximum Ppa and Raw, respectively. $\mathbf{a}$ : ovalbumin (OVA)/OVA; $\mathbf{\Lambda}$ : OVA/PBS; $\mathbf{\nabla}:$ PBS/OVA; $\bullet$ : PBS/PBS. Data are presented as mean \pm SEM $\left(n=4-5\right.$ each). Error bars are missing when falling into symbols. ${ }^{*}: p<0.05 ;{ }^{* *}: p<0.01 ;{ }^{* *}: p<0.001$ versus all other groups.

using the $\mathrm{IP}_{3}$ receptor antagonist xestospongin $\mathrm{C}$ did not affect the 5-HT induced vasoconstriction. In contrast, pre-treatment with the selective protein kinase C (PKC) inhibitor bisindolylmaleimide almost completely abolished 5-HT-induced vasoconstriction in lungs from sensitised and challenged mice. Furthermore, blockade of the Rho-kinase pathway by the highly selective Rho-kinase inhibitor Y-27632 resulted in a distinct reduction of the $P$ pa increase (fig. 6).

\section{DISCUSSION}

The main findings of the current study were as follows. 1) Allergic lung inflammation induced by allergen-sensitisation and -challenge caused impressive pulmonary vascular hyperresponsiveness to 5-HT in mice. 2) The increased vascular response to 5-HT was mediated by the Gq-coupled 5-HT2A receptor. 3) Allergen-induced pulmonary vascular hyperresponsiveness was not specific to 5-HT. 4) The intracellular signalling process in response to 5-HT involved PC-PLC and PKC, as well as Rho-kinase.

At present, the relevance of these findings for human disease remains unknown and it is not clear if allergen-induced pulmonary vascular hyperresponsiveness parallels airway hyperresponsiveness (a cardinal feature of asthma [25]) in humans.

However, pulmonary arterial vasoconstriction is regarded as an important early step in pulmonary hypertension $(\mathrm{PH})$ pathogenesis [7]. PH can be associated with diverse inflammatory diseases, including infections (HIV [26], human herpes virus 8 [27], schistosomiasis [28]) and autoimmune disorders (e.g. lupus erythematosus [29], scleroderma [30]), as well as COPD, suggesting a role for inflammatory mechanisms in $\mathrm{PH}$ [7]. In COPD, airway inflammation is assumed to affect the entire lung including the pulmonary vasculature [4], which might be relevant for $\mathrm{PH}$ pathogenesis. Moreover, in exacerbations of COPD triggered by respiratory infections, deterioration of cor pulmonale frequently occurs $[3,31]$.

There is only very little information concerning a link between allergic lung inflammation and pulmonary vascular responses, and the current study did not identify the exact mechanism. Due to the close vicinity of the pulmonary vessels and the airways, it is tempting to speculate that overspill of 


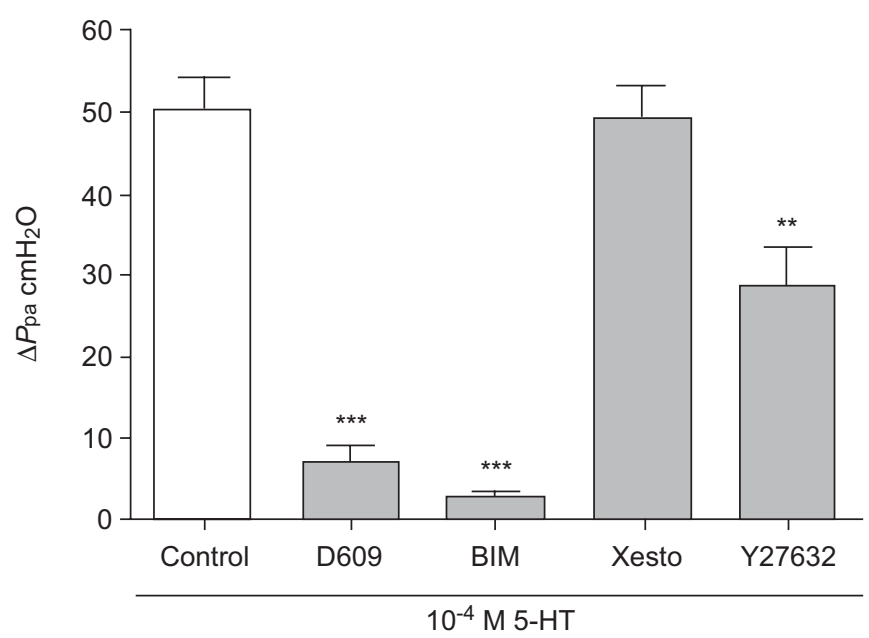

FIGURE 6. Increase of pulmonary arterial pressure $(P \mathrm{pa})$ in response to 5 hydroxytryptamine $(5-\mathrm{HT})$ in presence $(\square)$ or absence $(\square)$ of specific inhibitors for phosphatidylcholine-specific phospholipase C (D609; $10 \mu \mathrm{M})$, protein kinase $\mathrm{C}$ (bisindolylmaleimide (BIM); $10 \mu \mathrm{M}$ ), the inositol triphosphate receptor antagonist xestospongin $\mathrm{C}$ (xesto; $1 \mu \mathrm{M}$ ), or the Rho-kinase (Y27632; $5 \mu \mathrm{M}$ ). Mice were sensitised and challenged according to the protocol depicted in figure 1. Inhibitors were infused starting $10 \mathrm{~min}$ prior to perfusion with $5-\mathrm{HT}(100 \mu \mathrm{M})$. Difference in $\mathrm{Ppa}$ $(\triangle \mathrm{Ppa})$ was determined considering values $30 \mathrm{~s}$ before $5-\mathrm{HT}$ perfusion and at maximum $P$ pa. Data are presented as mean \pm SEM $\left(n=4\right.$ each). ${ }^{* *}: p<0.01$ versus control; $* * *: \mathrm{p}<0.001$ versus control.

inflammatory mediators [32] may contribute to vascular hyperresponsiveness. Notably, a recent study demonstrated that the alterations in the protein expression profile after allergen sensitisation and challenge partly correlated with those observed in hypoxia [33], which is known to induce PAH and increased vascular responses to vasoconstrictors [34, 35].

In a variety of airway inflammation models, perivascular immune responses were observed [12], and important features of airway remodeling were noted in the pulmonary vessels of allergen-sensitised and -challenged mice [15]. In order to investigate the impact of acute allergic lung inflammation on the pulmonary circulation, the current authors employed a well established murine model of acute allergen-sensitisation and challenge, which is characterised by several important features of allergic airway inflammation, including AR, eosinophil infiltration of the airways, and production of allergen-specific $\operatorname{IgE}[16,36]$. Histology showed peribronchial and perivascular leukocyte infiltrations, thus suggesting acute inflammation in the pulmonary vascular bed. Chronic allergen exposure, however, may have different biological impact on the pulmonary circulation, but was beyond the scope of the current study.

5-HT appears to be involved in the pathogenesis of PAH [7]. In the current model, 5-HT caused an immediate, dramatic $P$ pa increase in lungs of allergen-sensitised and -challenged mice in addition to enhanced bronchoconstriction. In control lungs, 5HT evoked only a moderate vascular pressor response, which is in line with previous studies [21]. Acute vasoconstriction to $5-\mathrm{HT}$ was mediated by the 5-HT1B receptor in human pulmonary arteries ex vivo [37] and in vivo [38], whereas in normal rat pulmonary arteries, these responses were mediated predominantly by the 5-HT2A receptor [39]. In ex vivo perfused lungs of allergen-sensitised and -challenged mice, as well as control mice, the 5-HT-evoked $P$ pa responses were blocked by the 5-HT2A receptor antagonist ketanserin, whereas 5-HT1B receptor antagonism by GR127935 did not diminish vasoconstriction. Moreover, the 5-HT1B/D receptor agonist sumatriptan (1-100 $\mu \mathrm{M})$ did not affect $P$ pa (data not given in detail). These results suggest an exclusive role of the 5-HT2A receptor, without the modulatory function of the 5-HT1B receptor described in chronic hypoxic rats [39] and mice [34], where 5-HT2A (Gq-coupled) and 5-HT1B (Gi-coupled) receptors were assumed to act synergistically [40].

In addition to 5-HT, thromboxane, endothelin-1 and angiotensin II, which also bind to G-protein coupled receptors in the pulmonary vasculature [40], have all been reported to cause acute pulmonary arterial vasoconstriction [21, 41, 42]. In the present study, low doses of the thromboxane receptor agonist U46619 caused an impressive Ppa response in lungs of allergen-sensitised and -challenged mice. As the employed doses were lower than reported to cause bronchial constriction in previous studies [21], airway resistance was only marginally affected by U46619. Therefore, a possible contribution of mechanical interaction between airway pressure and $P$ pa to the $P$ pa increase was excluded.

Furthermore, perfusion with endothelin-1 or angiotensin II also resulted in a pronounced arterial pressor response in OVA/OVA, as compared with PBS/PBS-lungs. Although these vasoconstrictors may not exclusively act via Gq-coupled receptors, the current results suggest an important role of this pathway.

Gq-coupled receptors activate PLC, thereby increasing cytosolic $\mathrm{IP}_{3}$ [43] and diacylglycerol (DAG). $\mathrm{IP}_{3}$ induces cytosolic $\mathrm{Ca}^{2+}$ increase, followed by myosin light chain (MLC) phosphorylation and subsequent smooth muscle contraction [43]. DAG activates PKC, leading to increased MLC phosphorylation via diverse mechanisms $[43,44]$. By using specific inhibitors, the current authors demonstrated that the enhanced $P$ pa response to 5-HT in allergen-sensitised and -challenged murine lungs was PC-PLC and PKC dependent. In contrast, the $\mathrm{IP}_{3}$-receptor antagonist xestospongin $\mathrm{C}$ did not influence the 5-HT-induced pressor response, although the employed concentration was three-fold above $50 \%$ of the median inhibitory concentration [45]. However, at this concentration xestospongin prevented acetylcholine-induced calcium-signalling in lung slices [46] and attenuated platelet activating factorinduced oedema formation in isolated lungs [47].

Beyond $\mathrm{IP}_{3}$ and $\mathrm{PKC}$, activated Rho-kinase indirectly increases MLC phosphorylation contributing to additional contractile force of myofilaments without changes in $\mathrm{Ca}^{2+}$ concentration [48]. Pre-treatment with the highly selective Rho-kinase inhibitor Y27632 [49] reduced the enhanced pressor response significantly. Interestingly, augmented contribution of Rhokinase to airway smooth muscle contraction in allergensensitised guinea pigs has recently been described [50] Moreover, Rho-kinase was upregulated in carotid arteries of spontaneously hypertensive rats [51] and in coronary arteries of interleukin-1 $\beta$-treated pigs [52], leading to vascular hyperresponsiveness to 5-HT. Against this background, a role for the 
$\mathrm{Ca}^{2+}$ sensitising Rho-kinase pathway in allergen-induced pulmonary vascular hyperresponsiveness may be assumed.

Concerning the role of 5-HT in human airways, several issues remain unsettled. Interestingly, in addition to being implicated in $\mathrm{PH}$ pathogenesis, serum 5-HT levels were associated with clinical severity and pulmonary function in human asthma, and were increased in asthma attacks [53]. However, a contribution of elevated serum 5-HT to $\mathrm{PH}$ and right heart failure in acute severe human asthma is currently not known.

In conclusion, the present authors have shown that allergen sensitisation and inhalative challenge of mice, which is well established to induce allergic lung inflammation and airway hyperresponsiveness, results in distinct vascular hyperresponsiveness to different vasoconstrictive agonists. These results suggest that allergic inflammation of the lung may play a role in the pathobiology of pulmonary hypertension.

\section{REFERENCES}

1 Saetta M, Di Stefano A, Rosina C, Thiene G, Fabbri LM. Quantitative structural analysis of peripheral airways and arteries in sudden fatal asthma. Am Rev Respir Dis 1991; 143: 138-143.

2 Hale KA, Niewoehner DE, Cosio MG. Morphologic changes in the muscular pulmonary arteries: relationship to cigarette smoking, airway disease, and emphysema. Am Rev Respir Dis 1980; 122: 273-278.

3 Barbera JA, Peinado VI, Santos S. Pulmonary hypertension in chronic obstructive pulmonary disease. Eur Respir J 2003; 21: 892-905.

4 Voelkel NF, Cool CD. Pulmonary vascular involvement in chronic obstructive pulmonary disease. Eur Respir J 2003; 22: Suppl. 46, 28s-32s.

5 Dorfmuller P, Perros F, Balabanian K, Humbert M. Inflammation in pulmonary arterial hypertension. Eur Respir J 2003; 22: 358-363.

6 Rubin LJ. Primary pulmonary hypertension. N Engl J Med 1997; 336: 111-117.

7 Humbert M, Morrell NW, Archer SL, et al. Cellular and molecular pathobiology of pulmonary arterial hypertension. J Am Coll Cardiol 2004; 43: Suppl. 12, 13S-24S.

8 Greiser E. Epidemiologic studies on the relation between use of appetite depressants and primary vascular pulmonary hypertension. Internist (Berl) 1973; 14: 437-442.

9 Mark EJ, Patalas ED, Chang HT, Evans RJ, Kessler SC. Fatal pulmonary hypertension associated with short-term use of fenfluramine and phentermine. N Engl J Med 1997; 337: 602-606.

10 Michelakis ED, Weir EK. Anorectic drugs and pulmonary hypertension from the bedside to the bench. Am J Med Sci 2001; 321: 292-299.

11 Wilson DW, Segall HJ, Pan LC, Lame MW, Estep JE, Morin D. Mechanisms and pathology of monocrotaline pulmonary toxicity. Crit Rev Toxicol 1992; 22: 307-325.

12 Pabst R, Tschernig T. Perivascular capillaries in the lung: an important but neglected vascular bed in immune reactions? J Allergy Clin Immunol 2002; 110: 209-214.

13 Henderson WR Jr, Tang LO, Chu SJ, et al. A role for cysteinyl leukotrienes in airway remodeling in a mouse asthma model. Am J Respir Crit Care Med 2002; 165: 108-116.

14 Singh B, Shinagawa K, Taube C, Gelfand EW, Pabst R. Strain-specific differences in perivascular inflammation in lungs in two murine models of allergic airway inflammation. Clin Exp Immunol 2005; 141: 223-229.

15 Tormanen KR, Uller L, Persson CG, Erjefalt JS. Allergen Exposure of Mouse Airways Evokes Remodeling of both Bronchi and Large Pulmonary Vessels. Am J Respir Crit Care Med 2005; 171: 19-25.

16 Hamelmann E, Schwarze J, Takeda K, et al. Noninvasive measurement of airway responsiveness in allergic mice using barometric plethysmography. Am J Respir Crit Care Med 1997; 156: 766-775.

17 Hamelmann E, Takeda K, Schwarze J, Vella AT, Irvin CG, Gelfand EW. Development of eosinophilic airway inflammation and airway hyperresponsiveness requires interleukin-5 but not immunoglobulin E or B lymphocytes. Am J Respir Cell Mol Biol 1999; 21: 480-489.

18 Hamelmann E, Oshiba A, Loader J, et al. Antiinterleukin-5 antibody prevents airway hyperresponsiveness in a murine model of airway sensitization. Am J Respir Crit Care Med 1997; 155: 819-825.

19 von Bethmann AN, Brasch F, Nusing $\mathrm{R}$, et al. Hyperventilation induces release of cytokines from perfused mouse lung. Am J Respir Crit Care Med 1998; 157: 263-272.

20 Seybold J, Thomas D, Witzenrath M, et al. Tumor necrosis factor-alpha-dependent expression of phosphodiesterase 2: role in endothelial hyperpermeability. Blood 2005; 105: 3569-3576.

21 Held HD, Martin C, Uhlig S. Characterization of airway and vascular responses in murine lungs. $\mathrm{Br} J$ Pharmacol 1999; 126: 1191-1199.

22 Skingle M, Beattie DT, Scopes DI, et al. GR127935: a potent and selective 5-HT1D receptor antagonist. Behav Brain Res 1996; 73: 157-161.

23 Luberto C, Hannun YA. Sphingomyelin synthase, a potential regulator of intracellular levels of ceramide and diacylglycerol during SV40 transformation. Does sphingomyelin synthase account for the putative phosphatidylcholine-specific phospholipase C? J Biol Chem 1998; 273: 14550-14559.

24 Hurwitz R, Ferlinz K, Sandhoff K. The tricyclic antidepressant desipramine causes proteolytic degradation of lysosomal sphingomyelinase in human fibroblasts. Biol Chem Hoppe Seyler 1994; 375: 447-450.

25 Global Initiative for Asthma. Global Strategy for Asthma Management and Prevention. NIH Publication No 02-3659. Bethesda, National Heart, Lung and Blood Institute and GINA Executive Committee, 2004.

26 Petitpretz P, Brenot F, Azarian R, et al. Pulmonary hypertension in patients with human immunodeficiency virus infection. Comparison with primary pulmonary hypertension. Circulation 1994; 89: 2722-2727.

27 Cool CD, Rai PR, Yeager ME, et al. Expression of human herpes virus 8 in primary pulmonary hypertension. $N$ Engl J Med 2003; 349: 1113-1122.

28 Bethlem EP, Schettino GP, Carvalho CR. Pulmonary schistosomiasis. Curr Opin Pulm Med 1997; 3: 361-365. 
29 Carreira PE. Pulmonary hypertension in autoimmune rheumatic diseases. Autoimmun Rev 2004; 3: 313-320.

30 Cool CD, Kennedy D, Voelkel NF, Tuder RM. Pathogenesis and evolution of plexiform lesions in pulmonary hypertension associated with scleroderma and human immunodeficiency virus infection. Hum Pathol 1997; 28: 434-442.

31 Weitzenblum E, Apprill M, Oswald M, Chaouat A, Imbs JL. Pulmonary hemodynamics in patients with chronic obstructive pulmonary disease before and during an episode of peripheral edema. Chest 1994; 105: 1377-1382.

32 Fernandes DJ, Mitchell RW, Lakser O, Dowell M, Stewart AG, Solway J. Do inflammatory mediators influence the contribution of airway smooth muscle contraction to airway hyperresponsiveness in asthma? J Appl Physiol 2003; 95: 844-853.

33 Fajardo I, Svensson L, Bucht A, Pejler G. Increased levels of hypoxia-sensitive proteins in allergic airway inflammation. Am J Respir Crit Care Med 2004; 170: 477-484.

34 Keegan A, Morecroft I, Smillie D, Hicks MN, MacLean MR. Contribution of the 5-HT(1B) receptor to hypoxia-induced pulmonary hypertension: converging evidence using 5-HT(1B)-receptor knockout mice and the 5-HT(1B/1D)receptor antagonist GR127935. Circ Res 2001; 89: 1231-1239.

35 Bonnet S, Belus A, Hyvelin JM, Roux E, Marthan R, Savineau JP. Effect of chronic hypoxia on agonist-induced tone and calcium signaling in rat pulmonary artery. Am J Physiol Lung Cell Mol Physiol 2001; 281: L193-L201.

36 Hamelmann E, Cieslewicz G, Schwarze J, et al. Antiinterleukin 5 but not anti-IgE prevents airway inflammation and airway hyperresponsiveness. Am J Respir Crit Care Med 1999; 160: 934-941.

37 Morecroft I, Heeley RP, Prentice HM, Kirk A, MacLean MR. 5-hydroxytryptamine receptors mediating contraction in human small muscular pulmonary arteries: importance of the 5-HT1B receptor. Br J Pharmacol 1999; 128: 730-734.

38 Hood S, Birnie D, Hillis S. The haemodynamic effects of subcutaneous sumatriptan, a 5HT1-receptor agonist. $\mathrm{Br} \mathrm{J}$ Clin Pharmacol 1997; 43: 327-328.

39 MacLean MR, Sweeney G, Baird M, McCulloch KM, Houslay M, Morecroft I. 5-Hydroxytryptamine receptors mediating vasoconstriction in pulmonary arteries from control and pulmonary hypertensive rats. $\mathrm{Br}$ J Pharmacol 1996; 119: 917-930.
40 MacLean MR. Pulmonary hypertension, anorexigens and 5-HT: pharmacological synergism in action? Trends Pharmacol Sci 1999; 20: 490-495.

41 Held HD, Uhlig S. Basal lung mechanics and airway and pulmonary vascular responsiveness in different inbred mouse strains. J Appl Physiol 2000; 88: 2192-2198.

42 Cargill RI, Lipworth BJ. The role of the renin-angiotensin and natriuretic peptide systems in the pulmonary vasculature. Br J Clin Pharmacol 1995; 40: 11-18.

43 Harnett KM, Biancani P. Calcium-dependent and calciumindependent contractions in smooth muscles. Am J Med 2003; 115: Suppl. 3A, 24S-30S.

44 Morgan KG, Leinweber BD. PKC-dependent signalling mechanisms in differentiated smooth muscle. Acta Physiol Scand 1998; 164: 495-505.

45 Gafni J, Munsch JA, Lam TH, et al. Xestospongins: potent membrane permeable blockers of the inositol 1,4,5-trisphosphate receptor. Neuron 1997; 19: 723-733.

46 Bergner A, Sanderson MJ. ATP stimulates Ca2+ oscillations and contraction in airway smooth muscle cells of mouse lung slices. Am J Physiol Lung Cell Mol Physiol 2002; 283: L1271-L1279.

47 Göggel R, Uhlig S. PAF-induced edema is mediated partly by activation of the inositol trisphosphate $\left(\mathrm{IP}_{3}\right)$-receptor. Am J Respir Crit Care Med 2000; 161: A418.

48 Somlyo AP, Somlyo AV. Signal transduction and regulation in smooth muscle. Nature 1994; 372: 231-236.

49 Uehata $M$, Ishizaki $\mathrm{T}$, Satoh $\mathrm{H}$, et al. Calcium sensitization of smooth muscle mediated by a Rho-associated protein kinase in hypertension. Nature 1997; 389: 990-994.

50 Schaafsma D, Gosens R, Bos IS, Meurs H, Zaagsma J, Nelemans SA. Allergic sensitization enhances the contribution of Rho-kinase to airway smooth muscle contraction. Br J Pharmacol 2004; 143: 477-484.

51 Mukai Y, Shimokawa H, Matoba T, et al. Involvement of Rho-kinase in hypertensive vascular disease: a novel therapeutic target in hypertension. FASEB J 2001; 15: 1062-1064.

52 Kandabashi T, Shimokawa H, Miyata K, et al. Inhibition of myosin phosphatase by upregulated rho-kinase plays a key role for coronary artery spasm in a porcine model with interleukin-1beta. Circulation 2000; 101: 1319-1323.

53 Lechin F, van der DB, Orozco B, Lechin M, Lechin AE. Increased levels of free serotonin in plasma of symptomatic asthmatic patients. Ann Allergy Asthma Immunol 1996; 77: $245-253$ 